\title{
Molecular Insights Into the Genetic Diversity and Population Structure of Artemisia Annua L. As Revealed by Insertional Polymorphisms
}

Negar Valizadeh ( $\nabla$ negarvz21@gmail.com )

University of Tabriz Faculty of Agriculture

Hossein Abbasi Holasou

University of Tabriz Faculty of Agriculture

Seyyed Abolghasem Mohammadi

University of Tabriz Faculty of Agriculture

Khalid Mahmood Khawar

Ankara University: Ankara Universitesi

Research

Keywords: Artemisia annua L, Genetic diversity, LTR Retrotransposon, model-based cluster

Posted Date: July 12th, 2021

DOI: https://doi.org/10.21203/rs.3.rs-683992/v1

License: (c) (i) This work is licensed under a Creative Commons Attribution 4.0 International License. Read Full License 


\section{Abstract}

\section{Background}

Retrotransposons-RTNs, are main source of variations in plant genomes that copying and pasting themselves into different transposon and work by changing RNA back into DNA via reverse transcription. For that reason, they are largely utilized in plants as optimum molecular markers to determine DNA fingerprinting, genetic mapping, and genetic variability.

Results

Inter-retrotransposon amplified polymorphisms (IRAPs) were used to measure genetic variability and structure in a collection of 118 sweet wormwood ( $A$. annua) accessions identifying and amplifying 849 loci using 32 IRAP primers, derived from Rosaceae, Gramineae, and Solanaceae retroelements. Single IRAP primer Tnt1.OL16 based on RTN produced the maximum count of markers. Percentage of polymorphic loci (PPL), mean expected heterozygosity $(\mathrm{He})$, number of effective alleles $(\mathrm{Ne})$ and information index (I) of Shannon, in the studied collection were $95.80 \%, 0.30,1.48$ and 0.46 , in the same order. AMOVA analysis showed nonexistence of significant genetic structures during structure analysis, however, the 4 populations had three clusters based on the $\mathrm{NJ}$ dendrogram that depicted a relatively higher level of genetic variation within each population. These clusters were approximately congruent with corresponding geographical distributions.

Conclusions

In conclusion, low genetic diversity of Iranian Sweet wormwood was detected that could be reduced through introduction of appropriate exotic or improved germplasm to reduce the effects of inbreeding depression.

\section{Background}

Medicinal Sweet wormwood (Artemisia annua L., $2 \mathrm{n}=18$ ), Persian vernacular name "Dermaneh" is a fast growing, branched plant species that reaches about $150 \mathrm{~cm}$ in height [1]. It is included among 35 species from genus Artemisia, family Asteraceae that are widely distributed throughout Iran [2-4] and is highly heterozygous [5]. It is also found in Australia, Central Asian, South East Asian and West Asian countries variably $[6,7]$.

The plant is used as source of obtaining artemisinin, that is an endoperoxide sesquiterpene lactone, with anti-malarial properties at concentrations of $0.01 \%-2 \%$ leaf dry weight [8]. Dried leaves of the plant are also a source of both essential oil (1.4-4.0\%) and other active metabolites like sesquiterpene lactones, flavonoids, polyalkynes, antioxidants and coumarins [9].

The exact prediction of genetic difference in a specific germplasm is important for efficient utilization, survival, evolution, and conservation of crop genetic resources improvement programs $[10,11]$. To begin 
with strategic crop improvement programs, information about inter and intra genetic variation among existing $A$. annua germplasm is crucial for their management as well as conservation and development of new cultivars with higher quantities of artemisinin and better quality of other secondary metabolites $[12,13]$. Genetic diversity among medicinal plants could be understood using molecular (DNA), phenotypic (morphological) and biochemical markers [14-16], but morphological markers are influenced by environmental determinants controlled by epistatic and pleiotropic gene effects and could show a little variation [14]. In contrast, the use of molecular markers are not influenced by the environment and overcome these disadvantages. The use and development of molecular markers for study of backcrosses, phylogenetic, population genetics, marker assisted selections, mapping of desired genes, analysis of genetic relationships, building linkage maps, the exploitation and detection of DNA polymorphism is being carried out in the subjects of molecular biology, biotechnology and genetics. There is need to carefully select any type of molecular markers. Because variations in their methodologies, applications and principles, need careful considerations before selecting them by their searchers. DNA-based molecular markers generate new probabilities of genome genotyping provided by beneficial molecular evidence to evaluate genetic diversity. Several researches have been performed to measure genetic diversity and structure of Artemisia species population worldwide during the last ten years, using RAPD [15-18], AFLP [1], ISSR [18-22], SSR [23] and EST-SSR markers [23, 24]. So far, only one study with significantly small native populations of $A$. annua collected from different areas of Northern Iran size has been studied using four AFLP markers, [1] for evaluation of genetic diversity.

Retrotransposons (RTNs) marker systems have not been previously used for evaluation of any sweet wormwood accessions in Iran. It is important to evaluate population structure and genetic diversity for these exceptionally rare resources. Therefore, this study was carried out to efficiently facilitate utilization and conservation of Iranian Sweet wormwood genotypes. To determine their genetic diversity and population structure along with determining their relationships at species level. Many features of RTNs, such as their ubiquity, activity, abundance and general dispersion in the plant genome, offer a tremendous foundation for the improvement of molecular marker systems [25, 26]. Different types of DNA molecular markers were developed from RTNs that most of RTNs are among the main sources of genetic diversity. Among them, inter RTN amplified polymorphism (IRAP) illuminates polymorphisms that amplifies segments between two close by long terminal repeats (LTRs) using primers complementary to the 3' end of a LTR sequence [25]. IRAP as a RTN based markers system with a high level of polymorphism are rarely used to investigate genetic diversity in medicinal plants such as Crocus [27], Leonurus cardiac L. [28], and Flax (Linum usitatissimum L.) [29, 30], Hypericum perforatum L. [31] taro (Colocasia esculenta), cocoyam (Xanthosoma sagittifolium) [32] and wild almond [33].

We used IRAP system marker to find activity of LTR RTN families in the Iranian Sweet wormwood after isolating them from barley, tobacco and apple. The aim of the research was to find desired RTN markers for checking diversity and characterize them for polymorphism of integration events through combing of the markers among 118 Sweet wormwood accessions that originated from four populations originating from different eco-geographical locations of Iran. 


\section{Results}

\section{Retrotransposon insertional polymorphism in sweet wormwood genome and IRAP analysis}

The study made use of 32 IRAP primers tested on 118 sweet wormwood accessions (Table 1) for initial screening. Among these primers, 12 single primers (Ty1-Copia, LTR6149, LTR6150, LTR1, Nikita, Sukkula,

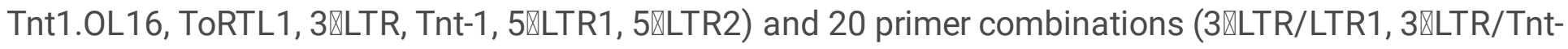
1, Bare1/LTR2, Nikita/LTR1, Nikita/Sukkula, Nikita/Ty1-Copia, Tnt-1/Sukkula, Tnt-1/5区LTR2, Tnt1.OL16/Ty1-Copia, Tnt1.OL16/Nikita, Tnt1.OL16/LTR6150, Tnt1.OL16/5『LTR1, Tnt1.OL16/5『LTR2, Tnt1.OL16/Sukkula, ToRTL1/Sukkula, ToRTL1/5هLTR2, LTR6150/5『LTR1, LTR6150/5هLTR2, 5囚LTR1/3囚LTR, 5囚LTR1/5囚LTR2) produced 849 distinguished and scored loci, out of 819 loci $(95.80 \%)$ that were polymorphic and that 14 primers, LTR6149, LTR1, Sukkula, Tnt1.OL16, 3øLTR, Tnt-1, 3区LTR/LTR1, 3邓LTR/Tnt-1, Bare1/LTR2, Nikita/LTR1, Nikita/Sukkula, Tnt-1/Sukkula, Tnt1.OL16/Ty1-Copia and ToRTL1/Sukkula, represented $100 \%$ polymorphism. The length of the amplified fragments differed in range of 100-3,000 bp, most of the band sizes had range of 500bp -2000bp. Single Primer Tnt1.OL16 generated the maximum amplified and polymorphic loci and showed the highest $\mathrm{Ne}$, He and I (Table 1, Supplementary Fig. 2). The lowest values of $\mathrm{Ne}, \mathrm{He}$ and I parameters were achieved for the primer combination ToRTL1/Sukkula. The number of scored loci for these primers ranged from 60 to 12 with a mean of 26.53 loci for each primer. Further detail of the primers is shown in Table 1. Supplementary Fig. 2 shows the banding pattern of Tnt1.OL16 and LTR1 primer in some sweet wormwood accessions. RTN activity and comparison of these families are shown in Table 2. 
Table 1

Characteristics of the IRAP primers used in this study

\begin{tabular}{|c|c|c|c|c|c|c|c|c|}
\hline Primer & TNB & NPB & PPB & $\mathrm{Ne}$ & I & $\mathrm{He}$ & $\begin{array}{l}\text { Annealing } \\
\text { temp. }\left(\mathbf{C}^{\circ}\right)\end{array}$ & $\begin{array}{l}\text { Band } \\
\text { size (bp) }\end{array}$ \\
\hline Ty1-Copia & 42 & 41 & 97.6 & 1.50 & 0.49 & 0.32 & 58 & $\begin{array}{l}100- \\
3000\end{array}$ \\
\hline LTR6149 & 18 & 18 & 100 & 1.56 & 0.48 & 0.32 & 65 & $\begin{array}{l}150- \\
2000\end{array}$ \\
\hline LTR6150 & 14 & 13 & 92.8 & 1.45 & 0.43 & 0.29 & 59 & $\begin{array}{l}250- \\
2000\end{array}$ \\
\hline LTR1 & 35 & 35 & 100 & 1.50 & 0.47 & 0.31 & 64 & $\begin{array}{l}150- \\
3000\end{array}$ \\
\hline Nikita & 20 & 19 & 95 & 1.44 & 0.43 & 0.27 & 65 & $\begin{array}{l}200- \\
2000\end{array}$ \\
\hline Sukkula & 23 & 23 & 100 & 1.52 & 0.48 & 0.31 & 64 & $\begin{array}{l}100- \\
3000\end{array}$ \\
\hline Tnt1.OL16 & 60 & 60 & 100 & 1.68 & 0.58 & 0.39 & 61 & $\begin{array}{l}100- \\
3000\end{array}$ \\
\hline ToRTL1 & 43 & 41 & 95.3 & 1.45 & 0.44 & 0.29 & 61 & $\begin{array}{l}100- \\
3000\end{array}$ \\
\hline 3囚LTR & 30 & 30 & 100 & 1.64 & 0.54 & 0.37 & 64 & $\begin{array}{l}200- \\
3000\end{array}$ \\
\hline Tnt-1 & 12 & 12 & 100 & 1.36 & 0.39 & 0.24 & 65 & $\begin{array}{l}200- \\
1500\end{array}$ \\
\hline 5खLTR1 & 15 & 13 & 86.7 & 1.41 & 0.40 & 0.26 & 61 & $\begin{array}{l}200- \\
2000\end{array}$ \\
\hline 5『LTR2 & 17 & 14 & 82.3 & 1.51 & 0.48 & 0.31 & 62 & $\begin{array}{l}150- \\
2000\end{array}$ \\
\hline 3区LTR/LTR1 & 24 & 24 & 100 & 1.55 & 0.49 & 0.32 & 64 & $\begin{array}{l}200- \\
3000\end{array}$ \\
\hline 3凶LTR/Tnt-1 & 33 & 33 & 100 & 1.51 & 0.48 & 0.31 & 64 & $\begin{array}{l}100- \\
2500\end{array}$ \\
\hline Bare 1/LTR2 & 28 & 28 & 100 & 1.64 & 0.55 & 0.37 & 61 & $\begin{array}{l}150- \\
2500\end{array}$ \\
\hline Nikita/LTR1 & 21 & 21 & 100 & 1.55 & 0.49 & 0.32 & 64 & $\begin{array}{l}150- \\
2000\end{array}$ \\
\hline
\end{tabular}

$T N B$ total number bands, NPB number of polymorphic bands, $P P B$ percentage of polymorphic bands, Ne effective number of alleles, I Shannon's information index, He expected heterozygosity 


\begin{tabular}{|c|c|c|c|c|c|c|c|c|}
\hline Primer & TNB & NPB & PPB & $\mathrm{Ne}$ & I & $\mathrm{He}$ & $\begin{array}{l}\text { Annealing } \\
\text { temp. }\left(\mathrm{C}^{\circ}\right)\end{array}$ & $\begin{array}{l}\text { Band } \\
\text { size (bp) }\end{array}$ \\
\hline Nikita/Sukkula & 33 & 33 & 100 & 1.42 & 0.41 & 0.26 & 58 & $\begin{array}{l}100- \\
3000\end{array}$ \\
\hline Nikita/Ty1-Copia & 21 & 20 & 95.2 & 1.50 & 0.48 & 0.31 & 59 & $\begin{array}{l}200- \\
2500\end{array}$ \\
\hline Tnt-1/Sukkula & 25 & 25 & 100 & 1.39 & 0.40 & 0.25 & 65 & $\begin{array}{l}150- \\
2000\end{array}$ \\
\hline Tnt-1/5囚LTR2 & 23 & 20 & 87 & 1.50 & 0.47 & 0.30 & 62 & $\begin{array}{l}200- \\
2000\end{array}$ \\
\hline $\begin{array}{l}\text { Tnt1.OL16/Ty1- } \\
\text { Copia }\end{array}$ & 42 & 42 & 100 & 1.31 & 0.36 & 0.21 & 58 & $\begin{array}{l}100- \\
2500\end{array}$ \\
\hline Tnt1.OL16/Nikita & 24 & 22 & 91.7 & 1.46 & 0.41 & 0.27 & 65 & $\begin{array}{l}100- \\
3000\end{array}$ \\
\hline Tnt1.OL16/LTR6150 & 15 & 14 & 93.3 & 1.43 & 0.41 & 0.29 & 65 & $\begin{array}{l}100- \\
1500\end{array}$ \\
\hline Tnt1.OL16/5『LTR1 & 21 & 20 & 95.2 & 1.49 & 0.46 & 0.30 & 60 & $\begin{array}{l}100- \\
2000\end{array}$ \\
\hline Tnt1.OL16/5هLTR2 & 26 & 24 & 92.3 & 1.51 & 0.48 & 0.31 & 59 & $\begin{array}{l}100- \\
2500\end{array}$ \\
\hline Tnt1.OL16/Sukkula & 17 & 16 & 94.1 & 1.41 & 0.44 & 0.31 & 60 & $\begin{array}{l}200- \\
2500\end{array}$ \\
\hline ToRTL1/Sukkula & 25 & 25 & 100 & 1.23 & 0.30 & 0.17 & 62 & $\begin{array}{l}150- \\
2500\end{array}$ \\
\hline ToRTL1/5囚LTR2 & 31 & 30 & 96.8 & 1.55 & 0.49 & 0.31 & 63 & $\begin{array}{l}100- \\
2500\end{array}$ \\
\hline LTR6150/5囚LTR1 & 34 & 32 & 94.1 & 1.56 & 0.49 & 0.31 & 60 & $\begin{array}{l}100- \\
3000\end{array}$ \\
\hline LTR6150/5囚LTR2 & 25 & 23 & 92 & 1.48 & 0.49 & 0.30 & 64 & $\begin{array}{l}100- \\
2500\end{array}$ \\
\hline 5囚LTR1/3囚LTR & 30 & 28 & 93.3 & 1.49 & 0.49 & 0.31 & 61 & $\begin{array}{l}100- \\
3000\end{array}$ \\
\hline 5囚LTR1/5खLTR2 & 22 & 20 & 90.9 & 1.48 & 0.47 & 0.30 & 61 & $\begin{array}{l}200- \\
2000\end{array}$ \\
\hline Total & 849 & 819 & - & - & - & - & - & - \\
\hline Average & 26.53 & 25.59 & 95.80 & 1.48 & 0.46 & 0.30 & - & - \\
\hline
\end{tabular}


Table 2

Comparison of RTN family in studied sweet wormwood (A. annua) accessions from Iran

\begin{tabular}{|lllllll|}
\hline RTN family & TL & PL & PPL & He & Ne & I \\
\hline Ty1-Copia & 105 & 103 & 98 & 0.28 & 1.44 & 0.44 \\
\hline LTR6149 & 18 & 18 & 100 & 0.32 & 1.56 & 0.48 \\
\hline LTR6150 & 88 & 82 & 93 & 0.30 & 1.48 & 0.45 \\
\hline LTR1 & 80 & 80 & 100 & 0.32 & 1.53 & 0.48 \\
\hline Nikita & 119 & 115 & 97 & 0.28 & 1.47 & 0.44 \\
\hline Sukkula & 123 & 122 & 99 & 0.26 & 1.39 & 0.41 \\
\hline Tnt1.OL16 & 205 & 198 & 97 & 0.30 & 1.47 & 0.45 \\
\hline ToRTL1 & 99 & 96 & 97 & 0.26 & 1.41 & 0.41 \\
\hline 3区LTR & 117 & 115 & 98 & 0.33 & 1.55 & 0.50 \\
\hline Tnt-1 & 93 & 90 & 97 & 0.27 & 1.44 & 0.43 \\
\hline 5囚LTR1 & 122 & 113 & 93 & 0.30 & 1.49 & 0.46 \\
\hline 5囚LTR2 & 144 & 131 & 91 & 0.30 & 1.50 & 0.48 \\
\hline LTR2 & 28 & 28 & 100 & 0.37 & 1.64 & 0.55 \\
\hline Bare 1 & 28 & 28 & 100 & 0.37 & 1.64 & 0.55 \\
\hline $\begin{array}{l}\text { TL Total loci, } P L \text { Polymorphic loci, } P P L \text { Percentage of polymorphic loci, He Mean of expected } \\
\text { heterozygosity, Ne Number of effective alleles, IShannon's information index }\end{array}$ & \\
\hline
\end{tabular}

\section{Genetic diversity and population structure of Iranian sweet wormwood accessions}

The properties of amplified IRAP loci utilizing 32 IRAP primers are shown in the Table 3. The means (\%) of IRAP polymorphic loci in the population ranged 26.02 (East Azerbaijan) to 95.35 (Mazandaran) averaging 76.25. Number of private marker varied from zero in population East Azerbaijan to 6 in population Mazandaran with an average of 3.5. Population Golestan had the maximum genetic diversity $(\mathrm{He}=0.26, \mathrm{I}=0.40)$, followed by Gilan $(\mathrm{He}=0.24, \mathrm{I}=0.38)$, East Azerbaijan that noted the minimum genetic diversity indices $(\mathrm{He}=0.11, \mathrm{I}=0.16)$. To partition and evaluate total genetic variation within and among the populations, AMOVA was carried out that was based on four populations using 849 IRAP loci. Significant variations were detected within populations (PhiPT $=0.05, P \leq 0.010$ ). The level of genetic variation was higher within each population (94\%) in comparison to variations across populations (6\%) (Data not shown). Gene flow, as estimated by PhiPT [Nm = 0.25 (1/PhiPT)-1], was 3.987, that indicated that genetic variation does not exist among the natural $A$. annua populations. 
Table 3

Characteristics of amplified IRAP loci in the studied sweet wormwood ( $A$. annua) populations

\begin{tabular}{|lllll|}
\hline Parameters & Azerbaijan & Gilan & Golestan & Mazandaran \\
\hline Number of loci & 566 & 828 & 815 & 830 \\
\hline Percentage of polymorphic loci & 26.02 & 93.31 & 90.33 & 95.35 \\
\hline No of loci with frequency $\geq 5 \%$ & 566 & 794 & 779 & 775 \\
\hline Number of private loci & 0 & 3 & 5 & 6 \\
\hline No of less common loci $(\leq 25 \%)$ & 0 & 0 & 0 & 0 \\
\hline No of less common loci $(\leq 50 \%)$ & 0 & 58 & 51 & 57 \\
\hline Mean of heterozygosity & 0.11 & 0.24 & 0.26 & 0.22 \\
\hline Shannon's information index $(\mathrm{I})$ & 0.16 & 0.38 & 0.40 & 0.36 \\
\hline Number of effective alleles $(\mathrm{Ne})$ & 1.18 & 1.42 & 1.38 & 1.35 \\
\hline
\end{tabular}

To further elucidate and explain concepts the population structure, distance- and model-based cluster analyses we performed. Neighbor-Joining ( $\mathrm{NJ}$ ) clustering to check pattern of differences among 118 accessions. The un-weighted Neighbor-joining algorithm and Number of differences evolutionary distance coefficient sourced IRAP data that grouped 118 accessions of the four populations into three major clusters (Fig. 1). In the resulting tree, the accessions were mainly grouped based on their geographical origins with minor mixture. Cluster I was dominated by the accessions originated from Mazandaran population and consisted of the maximum number of accessions. In addition, three accessions from Gilan population namely Gilan-Raz Kan, Gilan-Rahim Abad and Gilan-Rahim AbadPolam were classified together in cluster I. Cluster II comprised the accessions originated from Gilan population along with the two accessions from East Azerbaijan. In addition, five accessions from Mazandaran population namely Mazandaran-Mzarostaq, Mazandaran-Shirag, Mazandaran-Ncka-Chaleh Pola, Mazandaran-Ramsar-Ezaki, Mazandaran-Ramsar-Garesmasar and two accessions from Golestan population namely Golestan-Tangrah2, Golestan-Jokleh Bandan were included in this cluster. The third cluster included most of the accessions from Golestan population along with the three accessions from Mazandaran population and three accessions from Gilan population.

To settle or find a solution to the pattern of variation, principal coordinate analysis (PCoA) was used to further elucidate relationships among the selected accessions and assess the population subdivisions. The PCoA bi-plot showed no distinguished cluster pattern for 118 sweet wormwood accessions studied (Fig. 2). The first three axes accounted for $27.00,19.13$ and $15.65 \%$ genetic variation in same order, explaining altogether $61.78 \%$ of the total variation. These results showed that Mazandaran population was distanced from Golestan population on axis 1. The accessions of Gilan population were scattered over a large area. The second coordinate could not well separate the accessions of Mazandaran, Gilan, 
Golestan and East Azerbaijan. Coordinates 1 and 2 un-abled a discrimination of all three clusters in the phylogenic dendrogram in combination. Color-codes of all accessions in 2-dimensional PCoA plot was in accordance with these population groups noted from the "structure" analyses (Fig. 3). Because only $61.78 \%$ of the differences in this study was added in the 1 st three coordinate components, the sweet wormwood germplasm was also analyzed utilizing the model-based method implemented in the software "structure". The accessions within a cluster were represented by unique colour while accessions with two different colours indicated admixed forms. The results detected the maximal $\Delta K$ at $K=2$ followed by $K=$ 7. The $\Delta K$ value reduced with increased $K$, without showing any peak of $\Delta K$ at $K>7$ (Fig. 3A). The guessed delta $K$ value was 222.23 for 118 sweet wormwood accessions, which represented two subpopulations. More" subgroups were noted at the value of $K=7$ (Fig. $3 \mathrm{C}$ ), that showed that genotypes admixture confirmed the PCA. Most of sweet wormwood accessions expressed populations admixture of four populations as shown in the structure analysis at $K=7$ (Fig. 3C).

\section{Discussion}

\section{RTN activity and insertional polymorphism in Iranian $A$. annua genome}

The main reason of the study was to build a base for the breeding of $A$. annua and find exact level of variation in Iranian populations of sweet wormwood due to the deficiency of enough available data on the subject. Transposable elements may affect the adaptation due to their ability to spread into a genome by self-duplication, and evolution potential of hosts using events like insertion mutations, gene interruption, increment of chromosomal rearrangements and gene expression [34]. Therefore, transposable element-based marker systems could provide authentic and reliable information regarding genotype identification and performances. Recently, Sorkheh et al. [33] exhibited that the molecular genetic diversities measured by RTNs were more than the values measured by amplified fragment length polymorphism (AFLP), of 18 wild almond species.

To date, the IRAP markers are not utilized to measure genetic diversity researches in Iranian $A$. annua accessions. In this study, 32 IRAP primers amplified polymorphic and clear separate banding patterns were utilized to study genetic diversity among 118 sweet wormwood accessions. Single IRAP primers Ty1-Copia, LTR6149, LTR6150, LTR1, Nikita, Sukkula, Tnt1.OL16, ToRTL1, 3囚LTR, Tnt-1, 5囚LTR1, 5囚LTR2 generated scoreable banding patterns, that indicated the presence and insertional activities of these elements in A. annua genome (Table 1). The multiplicity of IRAP primers bands Tnt1.OL16 favored the opinion that the LTR families, have tendency to induce clusters in $A$. annua genome [35]. Primers Bare1 and LTR2 were monomorphic or did not generate any banding presenting infrequent insertion or absence of these retroelements in the $A$. annua genome, but Bare 1 generated much more polymorphism in a combination with LTR2, showing the insertion of these two RTNs near or into each other in the $A$. annua genome. The insertion of Bare1 near the LTR2 and other RTNs has been reported in wild almond genome [33]. The application of the barley RTNs for genome analysis among closely related genera, across species lines, and even sometimes between plant families has been previously demonstrated (27, $31,33,36,37)$. Sorkheh et al. [33] indicated that LTR primers designed based on barley produced a high 
level of insertional polymorphism in wild almond and was active throughout evolution of Prunus species. Presence and insertional polymorphism of the Nikita, Sukkula, and Bare-1 elements in Hypericum perforatum has also been documented [31]. Du et al. [38] used RTN primers successfully. These were derived from Gramineae to identify and characterize 13 fruit crops and described that RTN sequences were isolated from one species can be utilized in another plant species.

The high percentage (\%) of polymorphism noted by IRAP (95\%) markers proposed activities of the RTN families used in the Iranian sweet wormwood genome in our study. Several studies describe the highly distinguished variations in RTN contents under several abiotic and biotic stress conditions that increased genome size $[39,40]$. Sorkheh et al. [33] observed same primers to describe relationships and genetic diversity across wild almond species obtained from west, north-west and central Iran that described that barley RTN based primers showed more distinguished participation to express genetic diversity among the Iranian species.

\section{Genetic characterization and relationship of sweet wormwood accessions}

The mean value of expected heterozygosity $(\mathrm{He})$, Shannon's Information index (I) and number of effective alleles $(\mathrm{Ne}),(0.21,0.32$ and 1.33 respectively) in the current study can be compared to that reported with Gaafar et al. [22], Huang et al. [20] and Huang et al. [41]. Huang et al. [20] in a study of genetic diversity among 290 China $A$. halodendron genotypes reported the high level of genetic variation $(I=0.323$, $\mathrm{Ne}=1.39$, and Nei's gene diversity $(h)=0.22$ ). In another study by Huang et al. [41], reported average values of $\mathrm{I}=0.32, \mathrm{He}=0.21, \mathrm{Ne}=1.33$ in Chinese materials. Studying the genetic diversity of Egyptian $A$. judaica by ISSR markers [22], the Nei gene diversity values were reported from 0.000 to 0.189 with an average value of 0.139 and the I values were varied between 0.000 to 0.278 with an average value of 0.199 . These relatively low values indicate moderate insertional activity of the used RTNs, significant inbreeding in the populations studied and nature of floral biology of $A$. annua, induce deadlock throughout process of $A$. annua evaluation and selection. In this study as regards four populations studied from any geographic region tend to have very similar genetic relationship indicating limited germplasm variation or interpopulation hybridization regionally. Another reason of low level of variability could be due to human practices such as trading of seeds. However, the strict selection pressure imposed due to genetic improvement results in eroding genetic diversity fully or partially.

AMOVA analysis revealed $94 \%$ variation to be within-populations, and $6 \%$ among-populations, it was concluded that the analyzed Sweet wormwood germplasm are genetically structured. In A. halodendron Huang et al. [20] reported vast genetic differences within-populations (90\%) than among populations (10\%). Similarly Huang et al. [41], reported $9 \%$ differences among populations compared to $91 \%$ variations within populations. Low level of variability among population can be explained that these populations share nearly the same gene pool and experience high connectivity, showing that genetic exchange within the population was higher, resulting in wide variation. Therefore, genetic variation between and within populations of a medicinal plant species can be very important for breeding and conservation. 
The PCoA (Fig. 2) and Bayesian analysis (Fig. 3) results also support weak divergence between these accessions. But clustering analysis based on NJ algorithm (Fig. 1) clearly discriminated the accessions in three main groups in concordance with geographical distribution of the genotypes. Most of the accessions from Mazandaran, Gilan and Golestan populations aggregated together in cluster I, II and III respectively. In addition two accessions from East Azerbaijan located in cluster II. In an analysis of genetic diversity of Judean wormwood populations collected from Egypt by Gaafar et al. [22] using ISSR markers, clustering according to geographical origin was evident. Principal coordinate analysis (PCOA) demonstrated spatially the relative genetic distances among the individual accessions. The plane of the first three PCoA axes accounted for $61.78 \%$ of the total variation (first axis $=27.00 \%$, second $=19.13 \%$, third $=15.65 \%$ ). Most of accessions from Mazandarn population along with a number of accessions from Gilan population clustered separately on the left plane. The total accessions from Golestan population along with a number of accessions from Gilan population clustered together on the left plane. Population structure analysis showed genotypes grouped into 3 subpopulation at $K=2$ and more division took place at $K=7$ indicating that all accessions were genetically taken from 7 subpopulations. Any association or relationship with place of origin was not detected among the accessions despite the accessions were collected from separate and distinguished geographical regions of Iran. Population genetic structures were affected by many factors, including fragmentation of habitat, breeding system, gene flow and mechanism of seed dispersal [42]. If gene flow $(\mathrm{Nm})<1$, the population/s is/are highly susceptible to genetic drift [43]. The average $\mathrm{Nm}$ value of natural $A$. annua is 3.987 , which indicated that genetic variation of $A$. annua is due to gene drift among inter-populations, and the influence of the gene flow within the populations was non-significant.

\section{Conclusion}

This study evaluated the population structure, genetic diversity, and relationships of $A$. annua germplasm across Iran using 18 IRAP primers. RTN-based markers are being used newly and are yet to be exploited fully. This approach can provide comprehensive information about level of genetic diversity and population structure of $A$. annua which could be useful for conservation and management of $A$. annua germplasm genetic resource. Single IRAP primer Tnt1.OL16 showed more distinguished contribution in defining the genetic diversity of the studied taxon's or species and their segregation. These results described that the genetic diversity of Iranian Sweet wormwood is low and that makes it a distinct population for extraction of artemisinin, uniformly. However, low genetic diversity in the plant could lead to genetic depression in the plant and lead to number of genetic depression related problems. Therefore, it is important to increase the genetic base of Sweet wormwood germplasm in Iran from a place with significant genetic variation to carry out extended breeding studies or through introduction of exotic germplasm from a place with appropriate eco-geographical background or source population; as the plant is highly heterozygous, cross-pollinating plant with very self-pollination. This will conserve the plant and reduce loss of genetic diversity to improve the effects of inbreeding depression on these genotypes.

\section{Materials And Methods}




\section{Plant materials and DNA isolation}

This study included 118 Iranian sweet wormwood ( $A$. annua) accessions as plant material. Names of accessions, information about collection, and their geographical locations are presented in Supplementary Table 1 - Fig. 1. The seeds were sown in pots having 1-3 cm diameter filled with a mixture of peat and vermiculite in the greenhouse at temperature of $25 \pm 1^{\circ} \mathrm{C}$. Above ground leaves and stems were collected after about 4 weeks of growth followed by their instant freezing in $2 \mathrm{~mL}$ tubes using liquid nitrogen. Total genomic DNA from each sample was extracted using CTAB method [44]. The quality and quantity of DNAs was measured utilizing spectrophotometer (Bio- Photometer 6131, Eppendorf,

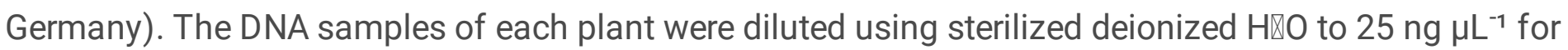
use in PCR amplification.

\section{IRAP analysis}

IRAP analysis was carried out using 14 LTR primers specifically designed and based on Rosaceae, Gramineae, and Solanaceae RTNs [45-48] (Supplementary Table 2) and their pair-wise combinations. PCR amplification was done in a $10 \mu \mathrm{L}$ reaction mixture with $2 \mu \mathrm{L}$ of genomic DNA, $4 \mu \mathrm{L}$ of Master Mix, $3 \mu \mathrm{l}$ of $\mathrm{ddH} \otimes \mathrm{O}$, and $1 \mu \mathrm{L}$ of each primer. Optimization of annealing temperature was carried out using gradient PCR. The cycling profile is described as; initial denaturation temperature $94^{\circ} \mathrm{C}$ for $300 \mathrm{sec} ; 40$ cycles of $94^{\circ} \mathrm{C}$ for $60 \mathrm{sec}, 50-65^{\circ} \mathrm{C}$ (annealing temperature according to primers; (Table 1) for $60 \mathrm{sec} ; 72^{\circ} \mathrm{C}$ for 120 sec; and final extension at $72^{\circ} \mathrm{C}$ for $420 \mathrm{sec}$. The PCR products were analyzed by $4 \%$ ultra-thin $(0.2 \mathrm{~mm})$ non-denatured polyacrylamide gel and checked using EtBr stain, utilizing a Gel-Scan 3000 electrophoresis system (Corbett, Sydney, Australia). Thermo Scientific GeneRuler 100 bp Plus DNA Ladder 100 to 3000 bp was utilized to estimate size of amplified fragments.

\section{Data analysis}

The absence ( 0 ) or presence (1) of clear and distinguishable amplified fragments were scored for IRAP analysis. Only well separated and bright bands were scored to compare the extent of the activity, variability and discriminating power of each RTN family, mean of expect heterozygosity (He), number of effective alleles ( $\mathrm{Ne})$, Shannon's information index (I) were calculated for each RTN family, and percentage (\%) of polymorphic bands (PPB), number of bands with $\geq 5 \%$ frequency number of private bands, number of less common bands with $\leq 25 \%$ and $50 \%$ frequency were calculated. AMOVA (Analysis of molecular variance) was carried out to separate the total genetic variation within and among origins based on IRAP data. Principal coordinate analysis (PCoA) was computed making use of genetic distances utilizing binary data described above implemented with GenAlEx 6.4 [49]. A cluster analysis helped to generate a dendrograms utilizing Neighbor Joining $(\mathrm{NJ})$ algorithm, Number of variations, evolutionary distance coefficient with MEGA 4.0 [50].

Pattern of the selected population structure in the selected accessions was analyzed with Bayesian cluster approach shown in Structure 2.3.1 [51]. Ten independent replications were used to set the number of subpopulations ( $k$ ) from 1 to 10, burn in period and MCMC iterations, both to 100,000, an admixture 
model and correlated allele frequencies. The optimal $K$ value (as true cluster number) was calculated by the posterior probability [In $\mathrm{P}(\mathrm{D})]$ and an ad hoc statistic $\Delta K$ based on the rate of change in $[\ln \mathrm{P}(\mathrm{D})]$ between successive $K$ [52] using the software Structure Harvester. Inferred ancestry estimates of genotypes (Q-matrix) were taken out for the selected subpopulations [51].

\section{Declarations}

\section{Acknowledgments}

The authors gratefully acknowledge the laboratory facilities provided by Genomics \& Molecular Breeding Lab, Center of Excellence in Cereal Molecular Breeding, University of Tabriz, Iran. The research was financially supported by the University of Tabriz incorporation with the Iran National Elites Foundation, under vote NO. 102-1565.

\section{Ethics approval and consent to participate}

Not applicable.

\section{Consent for publication}

All authors agree to publication.

\section{Availability of data and materials}

The data are available on request.

\section{Competing interests}

The authors declare that they have no competing interests.

\section{Funding}

This research was financially supported by the University of Tabriz incorporation with the Iran National Elites Foundation, under vote NO. 102-1565.

\section{Author contributions}

Concept and design of the experiment: NV, HAH, and SAM, Data analysis: HAH, NV and SAM, Writing the manuscript: HAH, NV, SAM and KMK.

\section{References}

1. Bovard R, Naghavi MR, Omidi M, Torabi S, Rezazadeh Sh, Hariri Akbari F, Shafie Alavijeh M, Behjat SB, Parvaneh S, Safakish Kashani MB. The study of genetic diversity in different plant populations of Artemisia anuua L. native to northern Iran by molecular marker AFLP. J B E S. 2016;9:51-59. 
2. Abad MJ, Bedoya LM, Apaza L, Bermejo P. The Artemisia L. genus: a review of bioactive essential oils. Molecules. 2012;17:2542-2566.

3. Bora K, Sharma A. The genus Artemisia: A comprehensive review. Pharm Biol. 2011;49:101-109.

4. Song $\mathrm{M}, \mathrm{Li} \mathrm{J}$, Xiong $\mathrm{Ch}$, Liu H, Liang J. Applying high-resolution melting (HRM) technology to identify five commonly used Artemisia species. Sci Rep. 2016;6:34133 https://doi.org/ 10.1038/srep34133.

5. Shen Q, Zhang L, Liao Z, Wang S, Yan T, Shi P, Lv Z. The genome of Artemisia annua provides insight into the evolution of Asteraceae family and artemisinin biosynthesis. Mol plant. 2018;6:776-788.

6. Bhakuni RS, Jain DC, Sharma RP, Kumar S. Secondary metabolites of Artemisia annua and their biological activity. Curr Sci. 2001;80:35-48.

7. Tzeng TC, Lin YL, Jong TT, Chang CMJ. Ethanol modified supercritical fluids extraction of scopoletin and artemisinin from Artemisia annua L. Sep Purif Technol. 2007;56:18-24.

8. Muangphrom P, Seki H, Fukushima EO, Muranaka T. Artemisinin-based antimalarial research: application of biotechnology to the production of artemisinin, its mode of action, and the mechanism of resistance of Plasmodium parasites. J Nat Med. 2016;70:318-334.

9. Botsaris AS. Plants used traditionally to treat malaria in Brazil: the archives of Flora Medicinal. J Ethnobiol Ethnomed. 2007;3:3-18.

10. Kresovich S, Szewc-McFadden A, Bliek S, McFerson J. Abundance and characterization of simple sequence repeats (SSRs) isolated from a size-fractionated genomic library of Brassica napus L. (rapeseed). Theor Appl Genet. 1995;91:206-211.

11. Kabbaj H, Sall AT, Al-Abdallat A, Geleta M, Amri A, Filali-Maltouf A, Belkadi B, Ortiz R, Bassi FM. Genetic diversity within a global panel of Durum Wheat (Triticum durum) landraces and modern germpalsm reveals the history of allele's exchange. Front Plant Sci. 2017;8:1277.

12. Van Inghelandt $D$, Melchinger AE, Lebreton $C$, Stich B. Population structure and genetic diversity in a commercial maize breeding program assessed with SSR and SNP markers. Theor Appl Genet. 2010;120:1289-1299.

13. Kjaer A, Grevsen K, Jensen M. Effect of external stress on density and size of glandular trichomes in full-grown Artemisia annua, the source of anti-malarial artemisinin. AoB Plants. 2012;1:pls018 http://dx.doi.org/10.1093/aobpla/pls018.

14. Rao NK. Plant genetic resources: advancing conservation and use through biotechnology. Afr J Biotechnol. 2004;3:136-145.

15. Badr A, Abo El-Khier Z, Hegazi, G, El-Sawy AA. Genetic variation in seven natural populations of Artemisia judaica L. in south Sinai using RAPD markers. World Appl Sci J. 2012a;18:1475-1480.

16. Badr A, El-Shazly HH, Helail NS, Ghanim WE. Genetic diversity of Artemisia populations in central and north Saudi Arabia based on morphological variation and RAPD polymorphism. Plant Syst Evol. 2012b;298:871-886.

17. Nazar N, Mahmood T. Morphological and molecular characterization of selected Artemisia species from Rawalakot, Azad Jammu and Kashmir. Acta Physiol Plant. 2011;33:625-633. 
18. Nguyen HT, Inotai K, Radacsi P, Tavaszi-Sarosi S, Ladanyi M, Eva Zamborine-Nemeth E. Morphological, phytochemical and molecular characterization of intraspecific variability of wormwood (Artemisia absinthium L.). J Appl Bot Food Qual. 2017;90:238-245.

19. Mohsen H, Ali F. Study of genetic polymorphism of Artemisia herba-alba from Tunisia using ISSR markers. Afr J Biotechnol. 2008;7:44-50.

20. Huang W, Zhao X, Zhao X, Li Y, Lian J, Yun J. Relationship between the genetic diversity of Artemisia halodendron and climatic factors. Acta Oecol. 2014;55:97-103.

21. Karimi A, Hadian J, Farzaneh M, Khadivi-Khub A. Evaluation of genetic variability, rust resistance and marker-detection in cultivated Artemisia dracunculus from Iran. Gene. 2014;554:224-232.

22. Gaafar RM, Hamouda MM, Sayed Ahmed HI, El-Shazlyb HH, Badr A. Genetic differentiation in the medicinal plant Artemisia judaica L. populations in Saint-Catherine area, South Sinai, Egypt. Plant Gene. 2017;12:80-87.

23. Kumar J, Bajaj P, Mishra GP, Bala Singh Sh, Singh H, Naik PK. Utilization of EST-derived SSRs in the genetic characterization of Artemisia annua L. genotypes from Ladakh, India. Indian J Biotechnol. 2014;13:464-472.

24. Kumar J, Singh H, Mishra GP, Srivastava RB, Naik PK. Utilization of intron-flanking EST-specific markers in the genetic characterization of Artemisia annua genotypes from the trans-Himalayan region of Ladakh, Indian. J Environ Biol. 2012;33:991-997.

25. Kalendar R, Schulman AH. IRAP and REMAP for retrotransposon-based genotyping and fingerprinting. Nat Protoc. 2006;1:2478-2484.

26. Schulman A, Flavell A, Paux E, Ellis THN. The application of LTR retrotransposons as molecular markers in plants. Methods Mol Biol. 2012;859:115-153.

27. Alavi-Kia SS, Mohammadi SA, Aharizad S, Moghaddam M. Analysis of genetic diversity and phylogenetic relationships in crocus genus of Iran using inter-retrotransposon amplified polymorphism. Biotechnol Biotechnol Eq. 2008;22:795-800.

28. Soorni A, Nazeri V, Fatthi R, Khadivi-Khub A. DNA fingerprinting of Leonurus cardiaca L. germplasm in Iran using amplified fragment length polymorphism and interretrotransposon amplified polymorphism. Biochem Syst Ecol. 2013;50:438-447.

29. Smykal P, Bacova-Kerteszova N, Kalendar R, Corander J, Schlman AH, Pavelek M. Genetic diversity of cultivated flax ( Linum usitatissimum L.) germplasm assessed by retrotransposon-based markers. Theor Appl Genet. 2011;122:1385-1397.

30. Abbasi Holasou H, Abdollahi Mandoulakani B, Jafari M, Bernousi I. Use of IRAP and REMAP markers to interpret the population structure of Linum usitatissimum from Iran. Biolojgia. 2016;3:1-11 http://dx.doi:10.1515/biolog-2016-0042.

31. Asadkhani Mamaghani R, Mohammadi SA, Aharizad S. Transferability of barley retrotransposon primers to analyze genetic structure in Iranian Hypericum perforatum L. populations. Turk J Bot. 2015;39:664-672. 
32. Doungous $\mathrm{O}$, Kalendar R, Adiobo A, Schulman AH. Retrotransposon molecular markers resolve cocoyam (Xanthosoma sagittifolium) and taro (Colocasia esculenta) by type and variety. Euphytica. 2015; 206:541-554 http://dx.doi:10.1007/s10681-015-1537-6.

33. Sorkheh K, Koohi Dehkordi M, Ercisli S, Hegedus A, Halasz J. Comparison of traditional and new generation DNA markers declares high genetic diversity and differentiated population structure of wild almond species. Sci Rep. 2017;7:5966 https://doi.org/10.1038/s41598-017-06084-4.

34. Huan-Van A, Ruzic L, Maisonhaute C, Capy P. Abundance, distribution and dynamics of retro transposable elements and transposons: similarities and differences. Cytogenet Genome Res. 2005;110:426-440.

35. Vicient, CM, Kalendar R, Anamthawat-Jonnson K, Suoniemi A, Schulman AH. Structure, functionality, and evolution of the BARE-1 retrotransposon of barley. Genetica. 1999;107:53-63.

36. Sen A. Retrotransposon insertion variations in doubled haploid bread wheat mutants. Plant Growth Regul. 2016;81:325-333.

37. Sen A, Ozturk I, Yaycili O, Alikamanoglu S. Drought tolerance in irradiated wheat mutants studied by genetic and biochemical markers. J Plant Growth Regul. 2017;36:669-679.

38. Du XY, Hu QN, Zhang QL, Wang YB, Luo ZR. Transferability of retrotransposon primers derived from Persimmon (Diospyros kaki Thunb.) across other plant species. Genet Mol Res. 2013;12:1781-1795.

39. Vuorinen AL, Kalendar R, Fahima T, Korpelainen H, Nevo E, Schulman AH. Retrotransposon-based genetic diversity assessment in wild emmer wheat (Triticum turgidum ssp. Dicoccoides). Agronomy. 2018;8:107 http://dx.doi:10.3390/agronomy8070107.

40. Abdollahi Mandoulakani B, Yaniv E, Kalendar R, Raats D, Bariana HS, Bihamta MR, Schulman AH. Development of IRAP- and REMAP-derived SCAR markers for marker-assisted selection of the stripe rust resistance gene Yr15 derived from wild emmer wheat. Theor Appl Genet. 2014;128:211-219.

41. Huang W, Zhao X, Zhao X, Zhao H, Wang Sh, Lian J. A combined approach using ISSR and ITS analysis for the characterization of Artemisia halodendron from Horqin sandy land, northern China. Biochem Syst Ecol. 2011;39:346-351.

42. Ge XJ, Zhang LB, Yuan YM, Hao G. Strong genetic differentiation of the East-Himalayan Megacodon stylophorus (Gentianaceae) detected by intersimple sequence repeats (ISSR). Biodivers Conserv. 2005;14:849-861.

43. Xin-Hua H, Hong P, Li-Bao B, D Jie-Chun P, Feng L, Yang-Rui L. Genetic diversity of natural Myrica rubra Sieb.et Zucc populations in Guangxi revealed by ISSR markers. Agric Sci China. 2010;9:626632.

44. Ausubel FM, Brent R, Kingston RE, Moore DD, Seidman JG, Smith JA, Struhl K, Albright LM, Coen DM, Varki A. Current Protocols in Molecular Biology. John Wiley, New York; 1995.

45. Kalendar R, Flavell AJ, Ellis THN, Sjakste T, Moisy C, Schulman AH. Analysis of plant diversity with retrotransposon-based molecular markers. Heredity. 1999;106:520-530.

46. Tam SM, Mhiri C, Vogelaar A, Kerkveld M. Comparative analyses of genetic diversities within tomato and pepper collections detected by retrotransposon-based SSAP, AFLP and SSR. Theor Appl Genet. 
2005;110:819-831.

47. Teo CH, Tan SH, Ho CL, Faridah QZ, Othman YR, Heslop-Harrison JS, Kalendar R, Schulman AH. Genome constitution and classification using retrotransposon-based markers in the orphan crop banana. J Plant Biol. 2005;48:96-105.

48. Venturi S, Dondini L, Donini P and Sansavini S. Retrotransposon characterisation and fingerprinting of apple clones by S-SAP markers. Theor Appl Genet. 2006;112:440-444.

49. Peakall R, Smouse PE. GenAIEx 6: genetic analysis in Excel. Population genetic software for teaching and research. Mol Ecol Notes. 2006;6:288-295.

50. Tamura K, Dudley J, Nei M, Kumar S. MEGA4: Molecular evolutionary genetics analysis (MEGA) software version 4.0. Mol Biol Evol. 2007;24:1596-1599.

51. Pritchard JK, Stephens M, Donnelly P. Inference of population structure using multilocus genotype data. Genetics. 2000;155:945-959.

52. Evanno G, Regnaut S, Goudet J. Detecting the number of clusters of individuals using the software STRUCTURE: A simulation study. Mol Ecol. 2005;14:2611-2620.

\section{Figures}




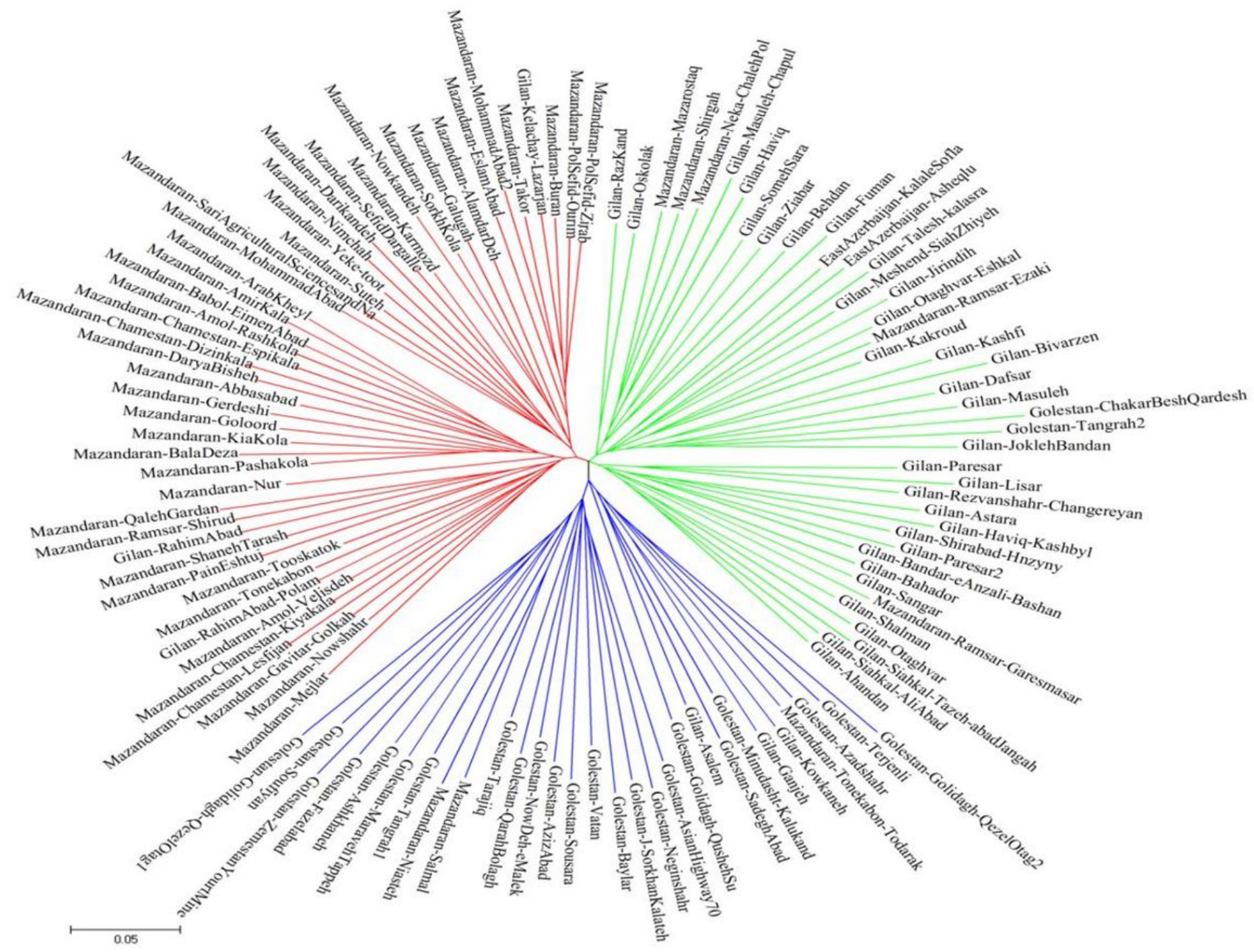

\section{Figure 1}

Grouping of 118 Sweet wormwood (A. annua) accessions based on IRAP data using Neighbor Joining clustering algorithm along with number of difference evolutionary distance coefficient. 


\section{Principal Coordinates}

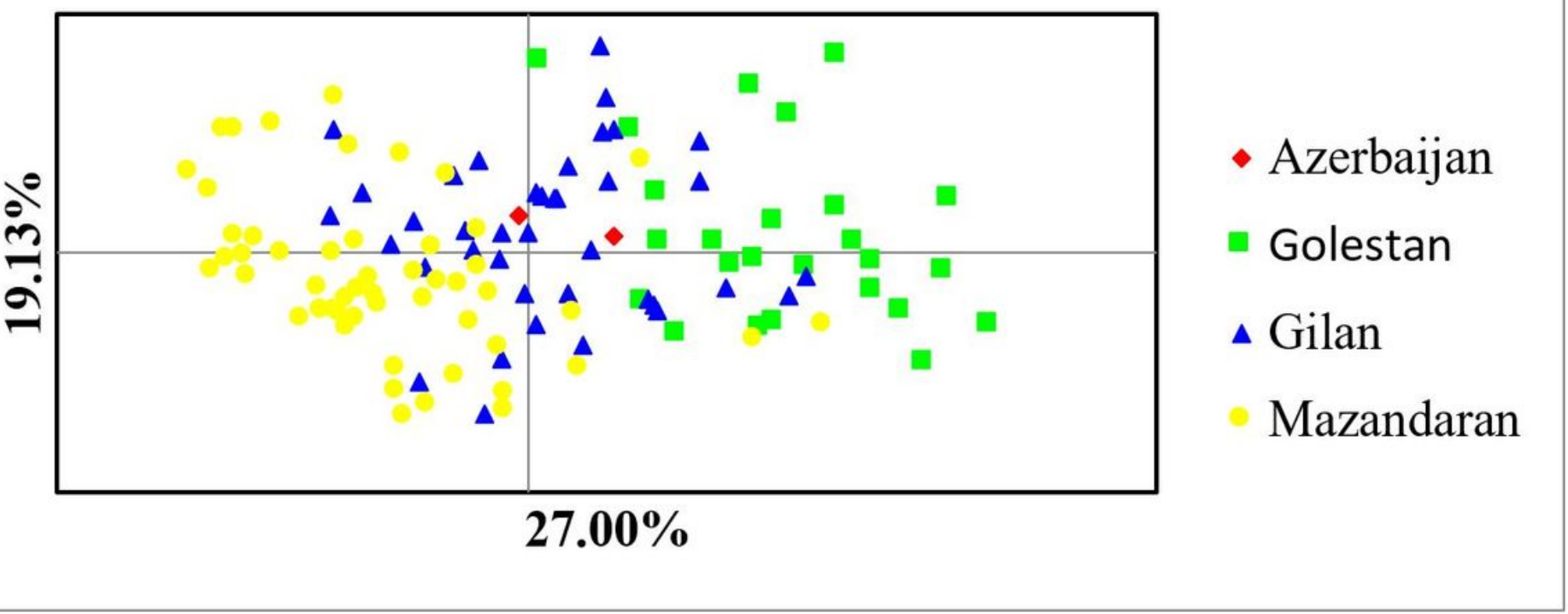

Figure 2

Principal coordinate analysis (PCoA) of 118 Sweet wormwood (A. annua) accessions based IRAP markers. Each individual in the study is represented by one dot, with a symbol color identical to the specified subgroup classification. 
A

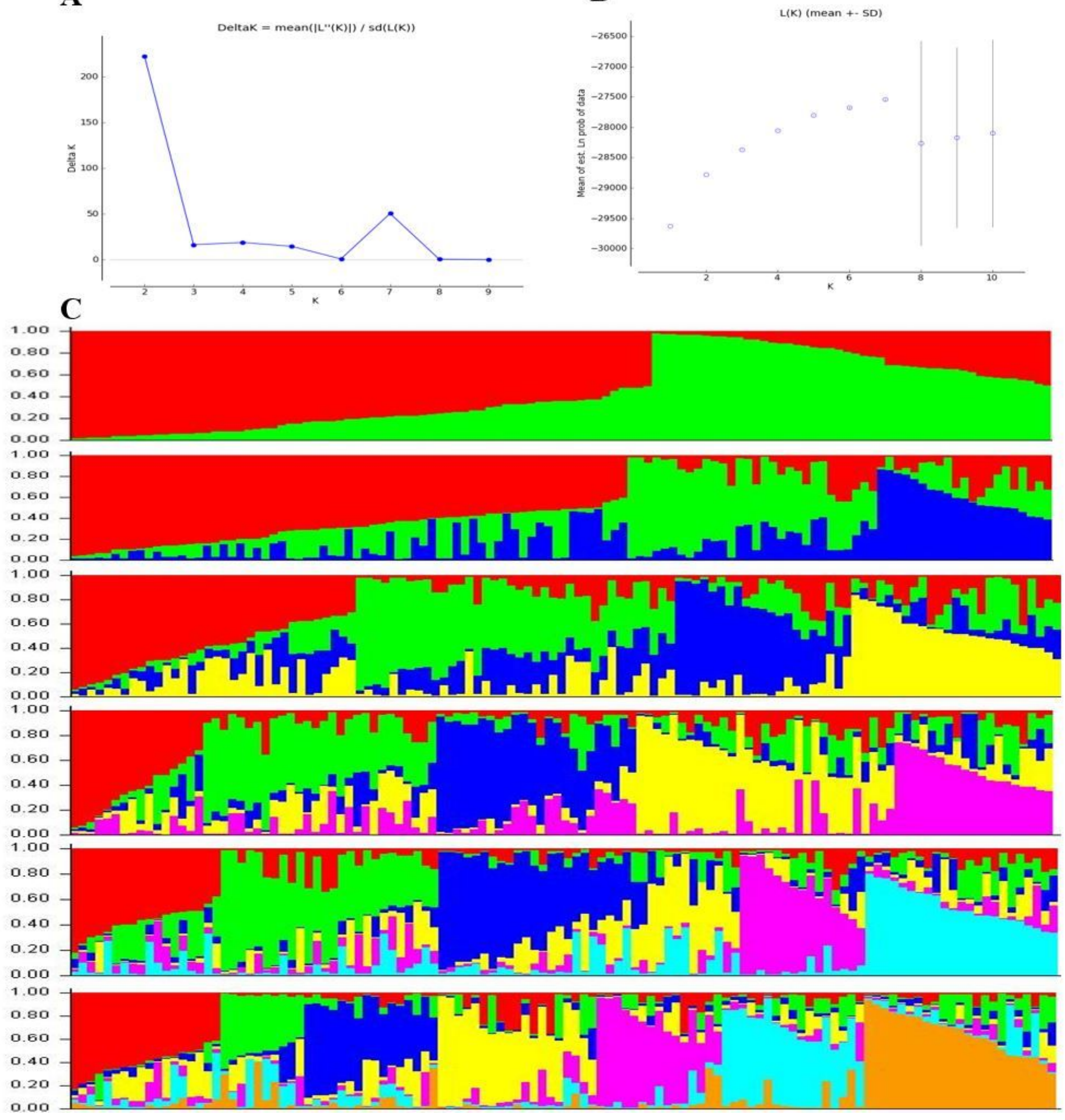

\section{Figure 3}

The pattern of population structure of the 118 Sweet wormwood (A. annua) accessions inferred using IRAP data. (A) Estimated $L n P(D)$ of possible clusters (K) from 1 to $10 ;(B) \Delta K$ based on the rate of change of $\mathrm{LnP}(\mathrm{D})$ between successive $\mathrm{K}$ and (C) Population structure based on $\mathrm{K}=2,3,4,5,6$ and 7 .

\section{Supplementary Files}


This is a list of supplementary files associated with this preprint. Click to download.

- Supplementarymaterial.docx 